\title{
MULTILAYER (TIN, TiAIN) CERAMIC COATINGS FOR NUCLEAR FUEL CLADDING
}

\author{
Ece Alat ${ }^{a, *}$, Arthur T. Motta a,b, Robert J. Comstock, Jonna M. Partezana ${ }^{c}$, and Douglas E. \\ Wolfe ${ }^{\text {a,d }}$ \\ ${ }^{a}$ Department of Materials Science and Engineering, The Pennsylvania State University, \\ University Park, PA 16802, USA \\ ${ }^{b}$ Department of Mechanical and Nuclear Engineering, The Pennsylvania State University, \\ University Park, PA 16802, USA \\ ${ }^{c}$ Westinghouse Electric Co., 1332 Beulah Rd, Pittsburgh, PA, USA \\ ${ }^{d}$ Applied Research Laboratory, The Pennsylvania State University, 119 Materials Research \\ Building, University Park, PA 16802, USA
}

\begin{abstract}
In an attempt to develop an accident-tolerant fuel (ATF) that can delay the deleterious consequences of loss-of-coolant-accidents (LOCA), multilayer coatings were deposited onto ZIRLO $^{\circledR} 1$ coupon substrates by cathodic arc physical vapor deposition (CA-PVD). Coatings were composed of alternating $\mathrm{TiN}$ (top) and $\mathrm{Ti}_{1-\mathrm{x}} \mathrm{Al}_{\mathrm{x}} \mathrm{N}$ (2-layer, 4-layer, 8-layer and 16-layer) layers. The minimum TiN top coating thickness and coating architecture were optimized for good corrosion and oxidation resistance. Corrosion tests were performed in static pure water at $360^{\circ} \mathrm{C}$ and 18.7 MPa for up to 90 days. The optimized coatings had no spallation/delamination and had a maximum of $6 \mathrm{mg} / \mathrm{dm}^{2}$ weight gain, which is 6 times smaller than that of a control sample of uncoated ZIRLO ${ }^{\circledR}$ which showed a weight gain of $40.2 \mathrm{mg} / \mathrm{dm}^{2}$. The optimized architecture features a $\sim 1 \mu \mathrm{m}$ TiN top layer to prevent boehmite phase formation during corrosion and a TiN/TiAlN 8-layer architecture which provides the best corrosion performance.
\end{abstract}

Keywords: Accident-tolerant fuel (ATF), corrosion resistance, oxidation resistance, multilayer ceramic coatings, TiN, TiAlN.

* Corresponding author. Tel.: +1 814865 9709, E-mail address: exa179@psu.edu (E. Alat)

${ }^{1}$ ZIRLO is a registered trademark of Westinghouse Electric Co. 


\section{Introduction}

Zirconium-based alloys are used in nuclear power reactors because of their low neutron absorption cross section, high temperature corrosion resistance, good mechanical properties and void swelling resistance [1,2]. However, zirconium-based nuclear fuel cladding alloys undergo waterside corrosion by the primary coolant water under normal operating conditions. As the amount of hydrogen generated in the corrosion reaction exceeds the hydrogen solid solubility limit of zirconium, hydride precipitation takes place in the cladding, which can lead to cladding embrittlement [3]. In the case of a loss-of-coolant-accident (LOCA), the cladding temperature may increase above $1200^{\circ} \mathrm{C}$ leading to a significant acceleration of the corrosion reactions and corresponding hydrogen generation. During the Fukushima-Daichii accident at the 2011 Japan earthquake and tsunami, the large amount of hydrogen generated through corrosion mechanism led to explosions in the reactor building, which severely worsened the accident development [4].

This issue has motivated research into Accident Tolerant Fuels (ATF), defined as fuels that provide additional coping time making external intervention possible before severe fuel damage occurs. ATF cladding concepts that have been proposed include bulk ferritic alloy steel cladding [5], bulk silicon carbide (SiC) [6], and others [7]. Although these concepts have the potential to be more tolerant in case of accidents, they would require major engineering design changes to the reactor cores. An alternative approach is to create a cladding with a protective coating. This approach would also improve corrosion performance and hydrogen pickup during normal operation, leading to further improved design safety. Several coating materials have been studied previously, including $\mathrm{SiC}, \mathrm{Ti}_{3} \mathrm{AlC}_{2}, \mathrm{Ti}_{3} \mathrm{SiC}_{2}, \mathrm{TiN}$ and TiAlN [8-10]. Among these, there has been two studies to assess the oxidation resistance of TiN and TiAlN coatings on zirconiumbased alloy substrates; one in which pulsed laser deposition (PLD) was used to put coatings on Zircaloy-4 [9] and other using cathodic arc physical vapor deposition (CA-PVD) to put coatings on a ZIRLO ${ }^{\circledR}$ substrate [11].

TiN and TiAlN coating applications on high-speed tool steels, cemented carbides, and cermet substrates for various cutting and finishing operations in the tooling industry have been studied for years [12-19]. Depending on its stoichiometry, TiN can provide chemical inertness 
[9] up to $600^{\circ} \mathrm{C}$ in air [19]. The $\mathrm{Al}$ incorporation into TiN, titanium aluminum nitride (TiAlN) provides high temperature oxidation resistance, advanced wear/abrasion resistance and improved toughness under extreme environments [20,21]. When $0.7>x>0.6$ for $\mathrm{Ti}_{1-\mathrm{x}} \mathrm{Al}_{\mathrm{x}} \mathrm{N}$, titanium nitride and aluminum nitride nanodomains co-exist, resulting in increased hardness and Young's modulus of the material $[19,22]$. It was also demonstrated that this composition leads to additional improvement in oxidation/corrosion resistance (upwards of $800-1000^{\circ} \mathrm{C}$ ), thermal stability, wear/abrasion resistance and toughness [12,19,23-25]. The increased oxidation resistance results from the formation of a thin, dense and protective oxidation barrier $\left(\mathrm{Al}_{2} \mathrm{O}_{3}\right)$ which reduces inward oxygen diffusion and outward aluminum diffusion in the protective film [19]. Because, oxidation initiation of TiAlN coating depends on the aluminum content, the increase of aluminum content improves oxidation resistance by shifting its commencement to higher temperatures [26].

In our previous study, monolithic TiN and TiAlN coatings deposited onto ZIRLO ${ }^{\circledR}$ cladding by CA-PVD with various deposition parameters were investigated to evaluate coating durability in a high temperature water environment [11]. It was determined that both types of coatings adhered well to a ZIRLO ${ }^{\circledR}$ substrate with a substrate surface roughness of $0.25 \mu \mathrm{m} \mathrm{R}_{\mathrm{a}}$ and a Ti bond coating layer with a thickness of $0.6 \mu \mathrm{m}$. Deposition parameters were optimized to achieve a coating which was able to withstand autoclave testing at $360^{\circ} \mathrm{C}$ and $18.7 \mathrm{MPa}$ saturation pressure for 3 days. However, non-uniform $\mathrm{AlO}(\mathrm{OH})$ - boehmite phase formation was observed on the surface of TiAlN coatings after the autoclave testing due to the reaction of water and resulted in depletion of aluminum from the coating. The formation of boehmite is detrimental to corrosion performance due to its high growth rate and poor adhesion which results in spallation and subsequent oxidation and recession of the coating. Boehmite formation was prevented when utilizing TiN layers which do not produce the boehmite phase. Thus, it was suggested to produce multilayer coatings with $\mathrm{TiN}$ as the exterior layer to act as a barrier for boehmite phase formation and benefit from advanced properties of both coatings in order to develop a coating with high temperature corrosion resistance. It should be noted that although TiAlN layer formed boehmite at relatively low temperatures, it is hypothesized that at high temperatures such as those experienced during a LOCA event TiAlN would not form boehmite and instead form a stable $\mathrm{Al}_{2} \mathrm{O}_{3}$. Recently Daub et al. [27] also demonstrated that TiAlN PVD 
coatings significantly reduce hydrogen uptake, which is beneficial for prevention of hydrogen embrittlement observed in zirconium alloys.

Multilayer coatings of TiN and TiAlN have been widely studied since they enhance properties such as hardness, wear resistance, and corrosion resistance [19,28-33]. The reason of increased hardness and wear resistance in multilayer structures was attributed to the dense and fine grain structure achieved by the interruption of the columnar grain structure due to nucleation of the successive layer, leading to large interfacial area [19]. Good corrosion resistance in multilayered coatings was attributed to the better scratch or crevice prevention possibility [34]. Additionally, it was also suggested that defects occurring in a single coating layer can be neutralized by the successive coating layer blocking the corrosive agent path.

In order to evaluate the performance of a coating in case of a LOCA condition, high temperature steam corrosion tests should be performed. In the current study, TiN and TiAlN multilayer coatings with various architectures were investigated at normal operation conditions to determine the minimum TiN top coating thickness necessary to avoid boehmite phase formation and to optimize damage tolerant coating architecture for good corrosion and oxidation resistance without any cracking or debonding.

\section{Experimental procedures}

\subsection{Materials and Coating}

Multilayer $\mathrm{Ti}_{1-\mathrm{x}} \mathrm{Al}_{\mathrm{x}} \mathrm{N}$ (where $\mathrm{x} \sim 0.54-0.67$ ) and $\mathrm{TiN}$ [henceforth referred to as TiAlN or TiN, respectively] coatings were deposited onto ZIRLO ${ }^{\circledR}$ coupons using CA-PVD. ZIRLO ${ }^{\circledR}$ has a nominal chemical composition of $1 \% \mathrm{Nb}, 1 \% \mathrm{Sn}, 300-600$ wt. ppm Fe and balance $\mathrm{Zr}$. Westinghouse provided cold-worked stress-relieved ZIRLO ${ }^{\circledR} 600$ micron sheet material for testing. The material showed the usual preferential orientation of the basal poles close to the normal direction along the transverse plane. Corrosion coupons measuring $2.54 \times 5.08 \mathrm{~cm}$ were prepared by cutting, and hand grinding with SiC paper having 240, 600 and 800 grit to achieve a final surface roughness of $0.25 \mu \mathrm{m} \mathrm{R}_{\mathrm{a}}$, (measured with a Mitutoyo SJ-201P Surface Roughness Tester) previously determined to be the optimum value to satisfy coating adhesion [11]. Sample 
edges and corners were also ground with 240 grit $\mathrm{SiC}$ paper. After each grinding operation, the following cleaning steps were performed: 10 minutes acetone exposure in an ultrasonic cleaner, deionized water rinse, 10 minutes methanol exposure in the ultrasonic cleaner and deionized water rinse, followed by drying with nitrogen gas. A $1.6 \mathrm{~mm}$ diameter hole was drilled near one edge of the sample for hanging on an autoclave tree during corrosion tests.

\subsection{Coating Deposition}

In this study, coatings were deposited by CA-PVD. In CA-PVD, the cathode which is the source of coating material is vaporized under arcing conditions that involves a high-current lowvoltage current passing between two electrodes (anode and cathode). This high current density induces vaporization, melting and molten or solid particle ejection, which results in arc erosion on the cathode surface [35]. A high percentage of the vaporized species are ionized and some of them are multiply charged [36].

CA-PVD has several advantages over other PVD processes such as higher kinetic energy of the depositing species leading to compressive residual stresses in the coating $[37,38]$ that help terminate crack propagation, tailorability of the interfacial products (especially in multilayer coatings), indistinct coating/substrate interface [19] and scalability to production size. The main disadvantage of CA-PVD is the macro sized metallic particles $(1-10 \mu \mathrm{m})$ either in the form of molten droplets of low melting point materials (Al in case of TiAlN) or of solid particles [35]. These particles may be entrapped within the coating during deposition leading to stress concentration and crack initiation or become incompletely ionized excess atoms which coalesce to macro-particles during flight towards the substrate [13,19,39]. Furthermore, thermal evaporation that may occur from these particles can result in thickness and composition variation in the film [35]. Studies to avoid these particles still continue.

The dimensions of the chamber used for the PVD in this study were $50.8 \mathrm{~cm} \mathrm{x} 50.8 \mathrm{~cm} \mathrm{x}$ $50.8 \mathrm{~cm}$ allowing good line-of-sight deposition at the deposition pressure. Cylindrical solid cathodes with a diameter of $6.3 \mathrm{~cm}$ and a thickness of $3.2 \mathrm{~cm}$ were used with two different compositions. One of these was a high purity (99.999\%) elemental titanium dished cylinder used 
for the titanium bond coating and for the TiN layer deposition. The other was titanium aluminum (33at.\% Ti - 67at.\% Al) used for the TiAlN layer deposition. These cathodes were oriented $180^{\circ}$ from each other with the ZIRLO $^{\circledR}$ coupons located between the cathodes with a spacing of 22.9 $\mathrm{cm}$. Magnets placed behind that cathodes served to control the plasma density and location. The samples were mounted in sample holders with shadow bars placed along the edge of each sample to avoid increased coating buildup along the sample edges. Then these sample holders were mounted on an 8-post planetary rotation setup. The substrate coupon temperature during deposition was $325^{\circ} \mathrm{C}$. The substrate deposition temperature was measured radiantly by a thermocouple located in close proximity of the samples during deposition. The placement of the thermocouple tip was located in the center of the chamber, parallel to the center of the deposition target (cathode), and in the center of the planetary rotation of the samples. The alignment of the thermocouple was $5 \mathrm{~cm}$ away from the center of each sample in the $\mathrm{x}-\mathrm{y}$ direction, and positioned in the center of the sample in the z-direction. For samples being deposited using the $2.5 \mathrm{~cm}$ riser, the thermocouple tip was located at the bottom edge of the samples with all other reference positions remaining the same.

Prior to deposition, sputter cleaning was performed to remove the native oxide from the substrate surface and improve coating adhesion by applying $1.6 \times 10^{-3} \mathrm{~Pa} \mathrm{Ar}$ atmosphere and $1000 \mathrm{~V}$ bias. The titanium-bond coating was deposited under argon atmosphere with a thickness of $0.6 \mu \mathrm{m}$, and a deposition rate of $0.75 \mu \mathrm{m} / \mathrm{min}$. The coating deposition was conducted under $1.6 \mathrm{~Pa} \mathrm{~N}_{2}$ atmosphere, with $-50 \mathrm{~V}$ bias, and an approximate deposition rate of $0.028 \mu \mathrm{m} / \mathrm{min}$ $(1.68 \mu \mathrm{m} /$ hour$)$. Coating properties specific for each sample are provided in Table 1 . The total coating thickness was around $10 \mu \mathrm{m}$ which for the elements used caused a negligible neutronic penalty realtive to uncoated ZIRLO [40]. Each layer at the top coat had approximately the same thickness, except E22, which has a thinner ( 1 micron) top layer. Accordingly, the layer thickness ranged from $0.7 \mu \mathrm{m}$ at the 16-layer sample to $6 \mu \mathrm{m}$ at the 2-layer sample.

Table 1: Cathodic Arc Physical Vapor Deposition Parameters for monolithic TiN and multilayer TiN/TiAlN coating fabrication.

\begin{tabular}{|c|l|l|l|l|l|c|}
\hline ID & Coating & \multicolumn{2}{|c|}{ \# of layers } & \multicolumn{2}{|c|}{$\begin{array}{c}\text { Deposition rate }(\mu \mathrm{m} \\
/ \mathrm{min})\end{array}$} & $\begin{array}{c}\text { Total coating } \\
\text { Thickness, } \\
(\mu \mathrm{m})\end{array}$ \\
\cline { 3 - 6 } & & TiN & TiAlN & TiN & TiAlN & \\
\hline
\end{tabular}




\begin{tabular}{|c|c|c|c|c|c|c|}
\hline E21 & TiN & 1 & & 0.018 & & 8.1 \\
\hline E22 & $\mathrm{TiN}\left(\right.$ thin) $/ \mathrm{Ti}_{1-\mathrm{x}} \mathrm{Al} \mathrm{l}_{\mathrm{x}} \mathrm{N}$ (thick) & 1 & 1 & 0.017 & 0.025 & 11.1 \\
\hline $\mathrm{E} 23$ & $\mathrm{TiN} / \mathrm{Ti}_{1-\mathrm{x}} \mathrm{Al}_{\mathrm{x}} \mathrm{N}$ 2-layer & 1 & 1 & 0.026 & 0.026 & 11.8 \\
\hline $\mathrm{E} 24$ & $\mathrm{TiN} / \mathrm{Ti}_{1-\mathrm{x}} \mathrm{Al}_{\mathrm{x}} \mathrm{N}$ 4-layer & 2 & 2 & 0.020 & 0.020 & 8.9 \\
\hline $\mathrm{E} 25$ & $\mathrm{TiN} / \mathrm{Ti}_{1-\mathrm{x}} \mathrm{Al}{ }_{\mathrm{x}} \mathrm{N}$ 8-layer & 4 & 4 & 0.022 & 0.022 & 9.8 \\
\hline E26 & $\mathrm{TiN} / \mathrm{Ti}_{1-\mathrm{x}} \mathrm{Al}_{\mathrm{x}} \mathrm{N}$ 16-layer & 8 & 8 & 0.024 & 0.024 & 10.9 \\
\hline
\end{tabular}

\subsection{Corrosion testing}

Corrosion testing was performed at Westinghouse in a static autoclave in pure water for 7-90 days at $360^{\circ} \mathrm{C}$ and saturation pressure, corresponding to $18.7 \mathrm{MPa}$ at this temperature. The autoclave material was 316 stainless steel. The corrosion tests were performed according to ASTM G2 standard practice. When reacted with water, Zr-based alloys form zirconium dioxide $\left(\mathrm{ZrO}_{2}\right)$ that remains on the surface of the sample, leading to an increase in the weight of the sample. The increase in the weight gain of the sample with respect to the oxide thickness can be approximated as $14.8 \mathrm{mg} / \mathrm{dm}^{2}=1 \mu \mathrm{m}$ [46]. Oxidation also causes weight gain in TiAlN and TiN. Weight gain measurements were performed following the autoclave test as a measure of corrosion, and the samples were examined visually using optical microscopy (OM).

The structural and morphological properties of samples tested for a longer duration (33 and 90 days) were further characterized using X-ray diffraction (XRD), scanning electron microscopy (SEM) and energy dispersive X-ray spectroscopy (EDS). Both frontal and crosssectional SEM/EDS analyses were performed. Frontal analyses were conducted directly after the autoclave test. Analyses of cross section of samples coated were conducted by cutting the samples in half, mounting in cold mount epoxy, grinding and polishing. X-ray diffraction (XRD) studies were conducted on a PANalytical XPert Pro Multi-Purpose Diffractometer (MPD) instrument with $240 \mathrm{~mm}$ radius, fixed divergence slit $\left(0.25^{\circ}\right)$, receiving slit $\left(0.25^{\circ}\right)$, using $\mathrm{Cu} \mathrm{K}_{\alpha}$ $\left(\mathrm{K}_{\alpha} 1=1.54056 \AA, \mathrm{K}_{\alpha} 2=1.54443 \AA\right)$ radiation. XRD analysis with Grazing Incidence (GI) and Bragg-Brentano (BB) scans were performed with a step size of $0.026^{\circ}$ two-theta to reveal the phases formed during corrosion. GI scans were conducted at incidence angles of $0.5^{\circ}, 1^{\circ}, 5^{\circ}, 10^{\circ}$ or $15^{\circ}$ to achieve the appropriate depth of penetration for the incident beam and to be able to distinguish phases at different layers of the coating. The penetration depth was estimated using PANalytical High Score software. Backscatter and secondary electron scanning electron 
microscopy (SEM) measurements were conducted using a FEI Quanta 200 Environmental SEM at $80 \mathrm{~Pa}$ pressure and $20 \mathrm{kV}$ high voltage.

\section{Results and Discussion}

Our previous work [11] showed that monolayer TiN and TiAlN coatings adhered well to ZIRLO $^{\circledR}$ substrate with a surface roughness of $0.25 \mu \mathrm{m} \mathrm{R}_{\mathrm{a}}$ and a $0.6 \mu \mathrm{m}$ thick Ti bond coating layer. Hence, coatings in this study were deposited onto substrates with the specified surface roughness and a titanium bond coating layer with the specified thickness. The same study [11] also showed that non-uniform boehmite phase formed on the surface of TiAlN coatings after autoclave testing (Figure 1a) with depletion of aluminum from top $\sim 4 \mu \mathrm{m}$ region of the coating (Figure 1b). However, the surface of the autoclave tested TiN coating showed neither boehmite phase formation nor spallation/delamination or crack formation (Figure 1c). Figure 1d is a crosssectional backscattered electron SEM image which shows that TiN coating prevented oxide formation at the ZIRLO ${ }^{\circledR}$ interface. Accordingly, multilayered TiN/TiAlN coatings were deposited in this study. 

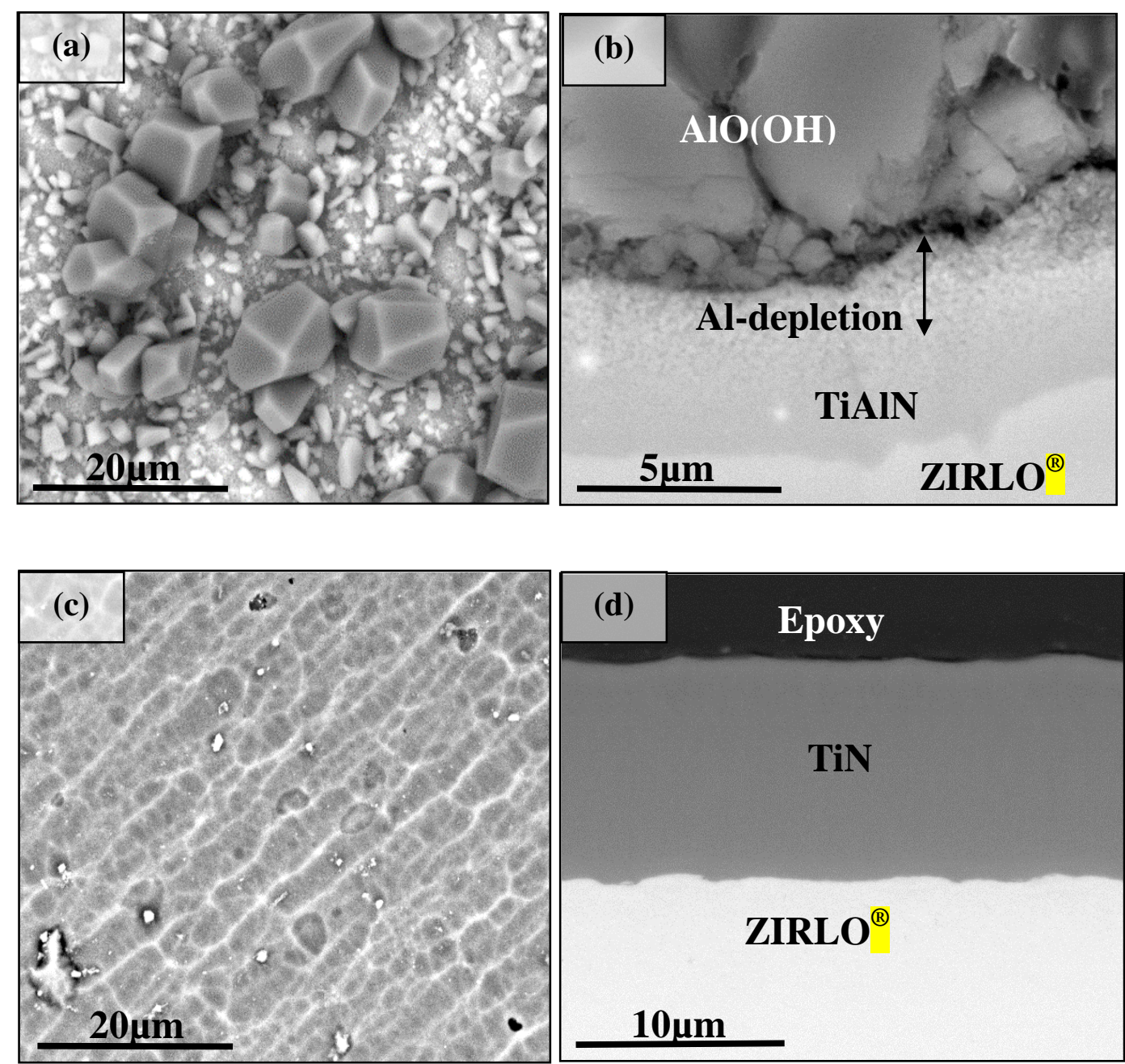

Figure 1: SEM- Back Scattered Electron (BSE) images of autoclave tested samples at $360^{\circ} \mathrm{C}$ and 18.7 MPa for 3 days; (a) TiAlN/Ti/ZIRLO ${ }^{\circledR}$ (10 $\mu$ in Ra) surface, (b) TiAlN/Ti/ZIRLO ${ }^{\circledR}(10 \mu$ in $\mathrm{Ra}$ ) polished cross section. Aluminum migration from the TiAlN coating is observed to have occurred in the top 4 microns of the TiAlN coating. The phase, boehmite (AlOOH), appears to have grown on the outer surface, above the TiAlN coating. The layers are 'wavy' because the ZIRLO $^{\circledR}$ substrate was roughened before coating deposition. (c) TiN/Ti/ZIRLO ${ }^{\circledR}$ (10 $\mu$ in Ra) surface, (d) TiN/Ti/ZIRLO ${ }^{\circledR}$ (10 $\mu$ in Ra) polished cross section. As shown by the polished cross sections, no boehmite phase is detected on the surface of the TiN coated sample. Figure reproduced from [24]

Multilayer coatings provide advanced functionality compared to the single layer coating by combining the beneficial properties of constituent coating layers. Multilayer architecture improves the corrosion tolerance of the coating, in other words when oxygen and hydrogen diffuses through one layer and forms boehmite phase resulting in the degradation and spallation of the exterior coating layer, the successive layers act as new barriers for oxygen and hydrogen ingress. 
Coating properties of the samples are shown in Table 1. The weight gain data of these coated samples and uncoated ZIRLO ${ }^{\circledR}$ presented in Figure 2 show that the coated samples had an order of magnitude lower weight gain compared to uncoated ZIRLO ${ }^{\circledR}$. This suggests that multilayer coating is capable of achieving better corrosion resistance than uncoated samples. The data also indicates that the multilayer architecture has a strong influence on corrosion, which means that the proper design of the multilayer is essential to achieve good corrosion protection. However, further analysis is required to evaluate whether this weight gain data were only due to oxidation or included spallation/delamination. Optical microscopy (OM) and scanning electron microscopy (SEM) coupled with energy dispersive X-ray spectroscopy (EDS) were performed to answer this and are presented later in this section.

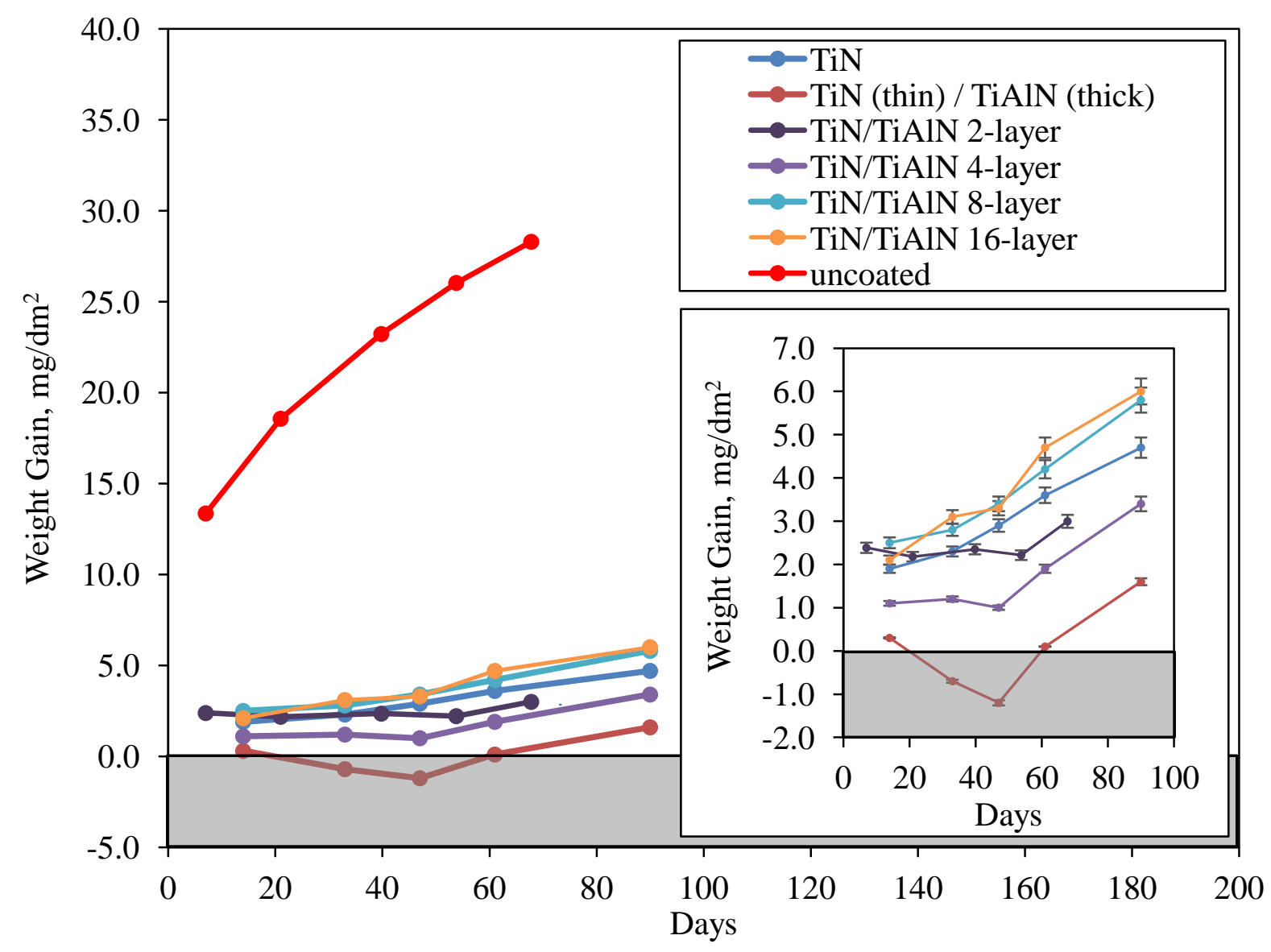

Figure 2. Weight gain $\left(\mathrm{mg} / \mathrm{dm}^{2}\right)$ as a function of time (days) for samples tested in autoclave at $360^{\circ} \mathrm{C}$ and $18.7 \mathrm{MPa}$ (saturation pressure). Multilayer design architectures show better corrosion resistance compared to uncoated ZIRLO ${ }^{\circledR}$ shown by the inset figure. 


\subsection{Autoclave tested samples for 7 days}

Cross-sectional OM images of samples corroded for 7 days in autoclave are shown in Figure 3, including both monolithic TiN (a) and multilayer samples (b-f). Cross-sectional images of as-deposited samples show that coating layers thicknesses were quite uniform. After the autoclave test, the coatings are not much altered, showing no delamination/spallation indicating that weight gain data can be directly related to oxidation. No boehmite phase formation was observed after the 7-day autoclave test in samples with the TiN top layer, as expected. Given these results it is considered that a $1 \mu \mathrm{m}$ thick TiN layer is enough to prevent boehmite phase formation.
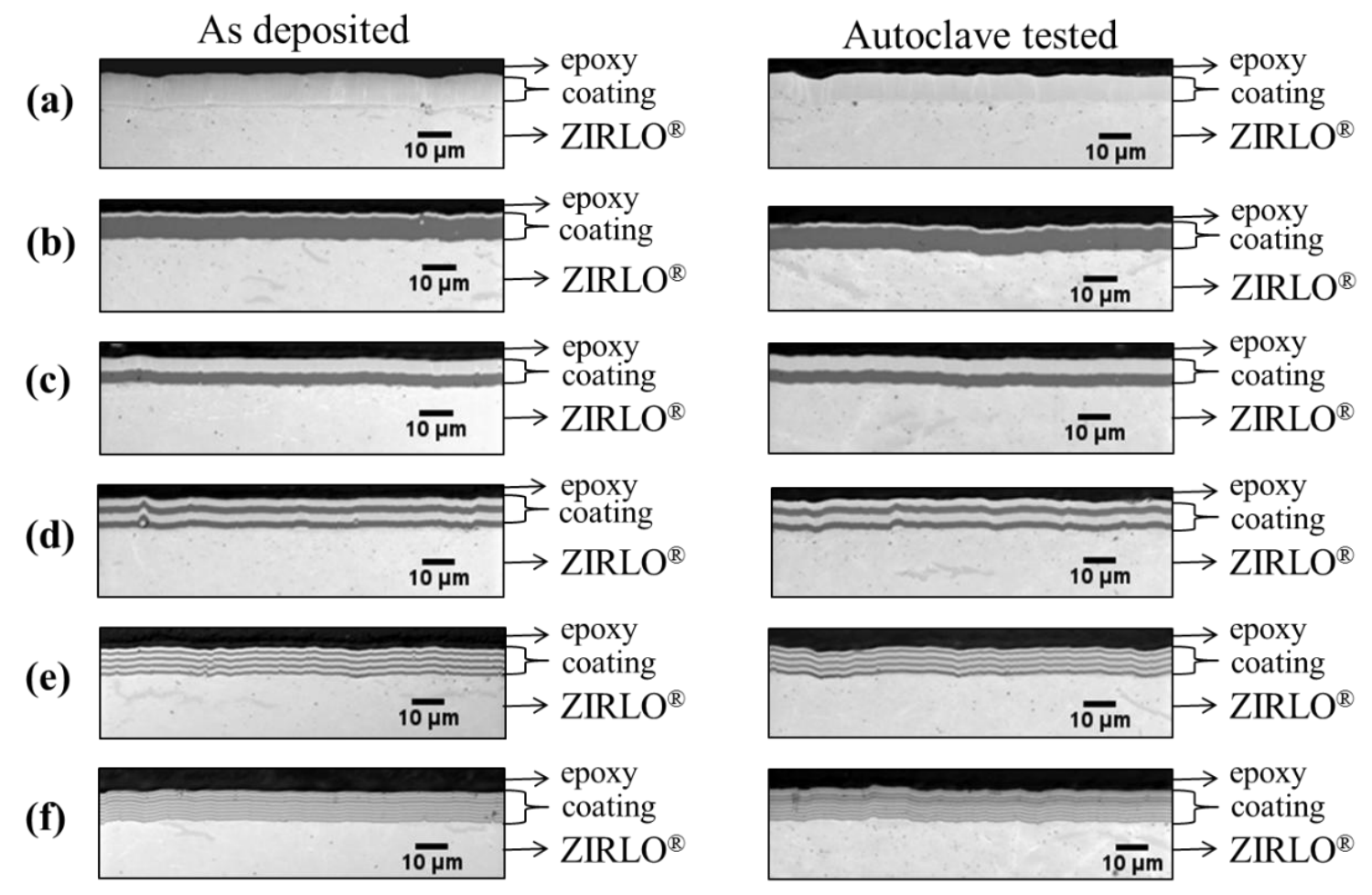

Figure 3. Optical images in the as-deposited condition (left) and after 7-day autoclave testing in $360^{\circ} \mathrm{C}$ water (right) for the cross sections of samples with coatings (a) E21-TiN, (b) E22TiN(thin)/TiAlN (thick), (c) E23-TiN/TiAlN 2-layer, (d) E24-TiN/TiAlN 4-layer, (e) E25TiN/TiAlN 8-layer, and (f) E26-TiN/TiAlN 16-layer. 


\subsection{Microscopic Characterization of 33-day Autoclave tested samples}

Characterization was also performed on samples that were autoclave tested for 33 days. While uncoated ZIRLO ${ }^{\circledR}$ showed a weight gain of $\sim 20 \mathrm{mg} / \mathrm{dm}^{2}$, coated samples showed weight gains around 1-3 mg/dm², again an order of magnitude lower than that of the uncoated sample.

Overall, the coatings were adherent to the ZIRLO ${ }^{\circledR}$ substrate. Most samples had stable coatings and showed positive weight gain, with the exception of TiN(thin)/TiAlN(thick), which indicates delamination/spallation in case of TiN (thin)/TiAlN (thick) coating, likely caused by non-uniform stresses due to coating thickness variation in each layer. A slight weight loss was observed in case of TiN/TiAlN 2-layer coated sample. Visual examination of one of the 2-layer coated samples revealed spallation. Digital and SEM images of one of these samples are provided in Fig. 4. As it can be observed from the digital image, spallation generally occurred at the edges, possibly due to non-uniform coating composition and thickness at the edges. Spallation was also observed on the surface at certain regions, as indicated on Figure 4. The SEM analysis performed on one of these regions (Fig. 4b) revealed that as a result of the spallation of the top TiN layer, TiAIN became in contact with the water in autoclave resulting in the boehmite phase formation. Note that in the regions where the coating layer is completely spalled, zirconium dioxide was formed.

(a)

(b)

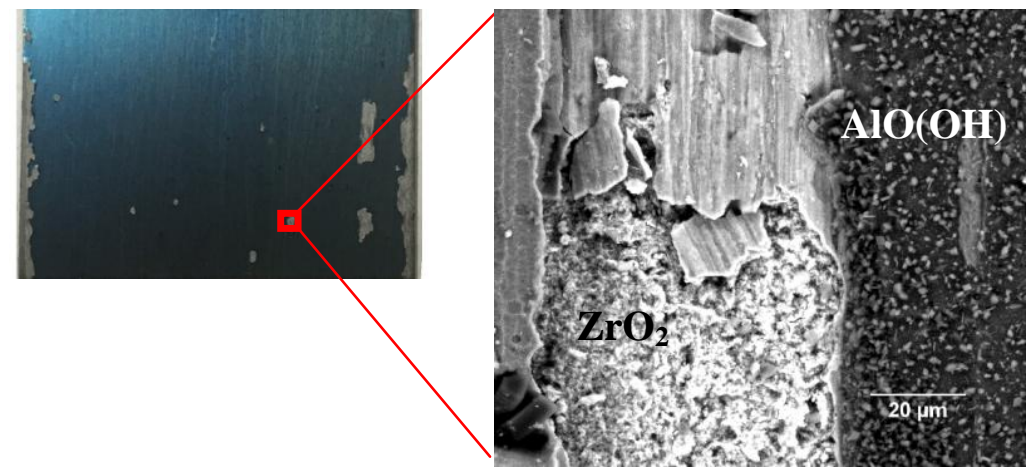

Figure 4. Spallation at a 2-layer coated sample after being autoclave tested for 33 days, (a) digital image, (b) SEM-BSE surface image.

The XRD Bragg-Brentano patterns showed the substrate phase as Zr (ICDD PDF\# 00005-0665), and some overlap of the $\mathrm{TiN}$ and anatase $\left(\mathrm{TiO}_{2}\right)$ peaks with $\mathrm{Zr}$ peaks. As expected, 
$\mathrm{Zr}$ peak intensities were very high compared to TiAlN and oxide phase peak intensities, due to larger volume of the substrate, making it difficult to analyze the pattern. Therefore, Grazing Incidence (GI) XRD was performed to better reveal the TiN, TiAlN and oxide phases. Several incident angles were used to separate the phases through the layers.

Figure 5 shows XRD GI patterns for E26 $\left(\mathrm{TiN} / \mathrm{Ti}_{1-\mathrm{x}} \mathrm{Al}_{\mathrm{x}} \mathrm{N}\right.$ 16-layer with $11.9 \mu \mathrm{m}$ coating thickness). For this sample, measurements were conducted using incident angles of $0.5^{\circ}, 1^{\circ}, 5^{\circ}$ and $10^{\circ}$. For penetration depth calculations, the density of TiN was assumed to be $5.4 \mathrm{~g} / \mathrm{cm}^{3}$ and TiAlN was assumed to be $4.8 \mathrm{~g} / \mathrm{cm}^{3}$. Accordingly, the corresponding penetration depths for the specified incident angles were calculated to be $\sim 0.5,1,3$ and $6 \mu \mathrm{m}$, respectively. The lower penetration depths $(0.5$ and $1 \mu \mathrm{m})$ made it possible to index the oxide phase peaks as coming from anatase $\left(\mathrm{TiO}_{2}\right.$, ICDD PDF\# 00-021-1272) and rutile ( $\mathrm{TiO}_{2}$, ICDD PDF\# 00-021-1276). Anatase and rutile are phases with same chemistry but different crystallographic space groups. As the penetration depth increased, it was possible to identify the peak intensities of $\operatorname{Ti}_{0.44} \mathrm{Al}_{0.56} \mathrm{~N}$ (ICDD PDF\# 01-080-4072) and TiN (ICDD PDF\# 04-015-0336).

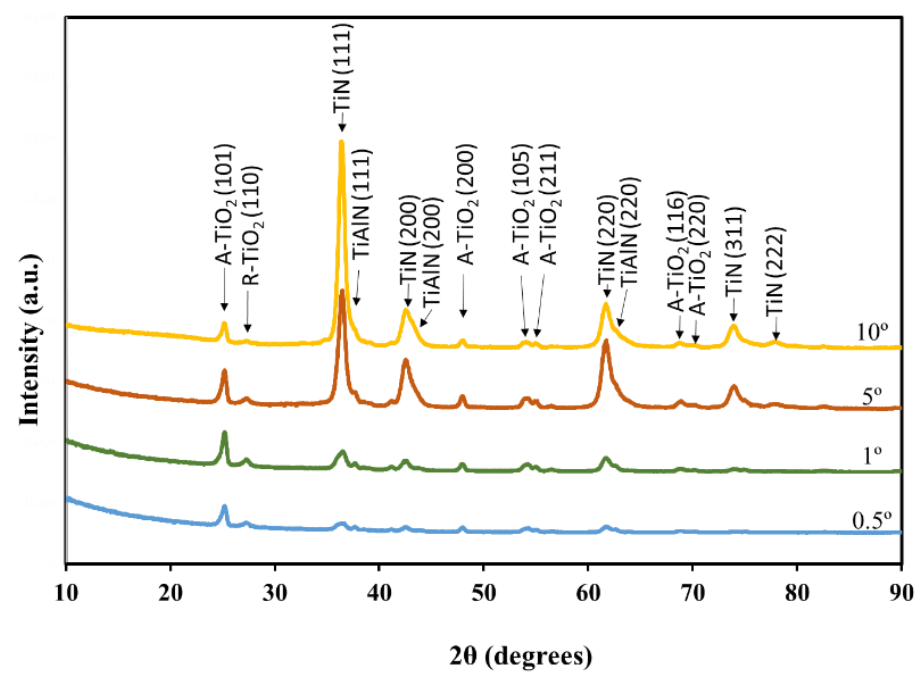

Figure 5. GI XRD patterns of sample E26 $\left(\mathrm{TiN} / \mathrm{Ti}_{1-\mathrm{x}} \mathrm{Al}_{\mathrm{X}} \mathrm{N}\right.$ 16-layer with $11.9 \mu \mathrm{m}$ coating thickness) that was exposed to the autoclave test at $360^{\circ} \mathrm{C}$ and saturation pressure of $18.7 \mathrm{MPa}$ for 33 days. GI XRD measurement was conducted with incident angles of $0.5^{\circ}, 1^{\circ}, 5^{\circ}$ and $10^{\circ}$. The corresponding penetration depth for specified incident angles were calculated to be $\sim 0.5,1$, 3 and $6 \mu \mathrm{m}$, respectively. Oxide phases were determined to be anatase $\left(\mathrm{A}-\mathrm{TiO}_{2}\right)$ and rutile $(\mathrm{R}$ $\left.\mathrm{TiO}_{2}\right)$. 
In order to better study and reveal the phases formed on the surface, GI patterns using a $1^{\circ}$ incident angle were obtained for all samples, as shown in Figure 6. Similar to the results presented in Figure 5, coating phases were identified as $\mathrm{Ti}_{0.44} \mathrm{Al}_{0.56} \mathrm{~N}$ (ICDD PDF\# 01-080-4072) and TiN (ICDD PDF\# 04-015-0336). Peaks associated with oxide phases were also observed (anatase (A) (ICDD PDF\# 00-021-1272), rutile (R) (ICDD PDF\# 00-021-1276), and $\mathrm{Ti}_{2} \mathrm{O}_{3}$ (ICDD PDF\# 04-002-0457)). No peaks from the boehmite phase were observed.

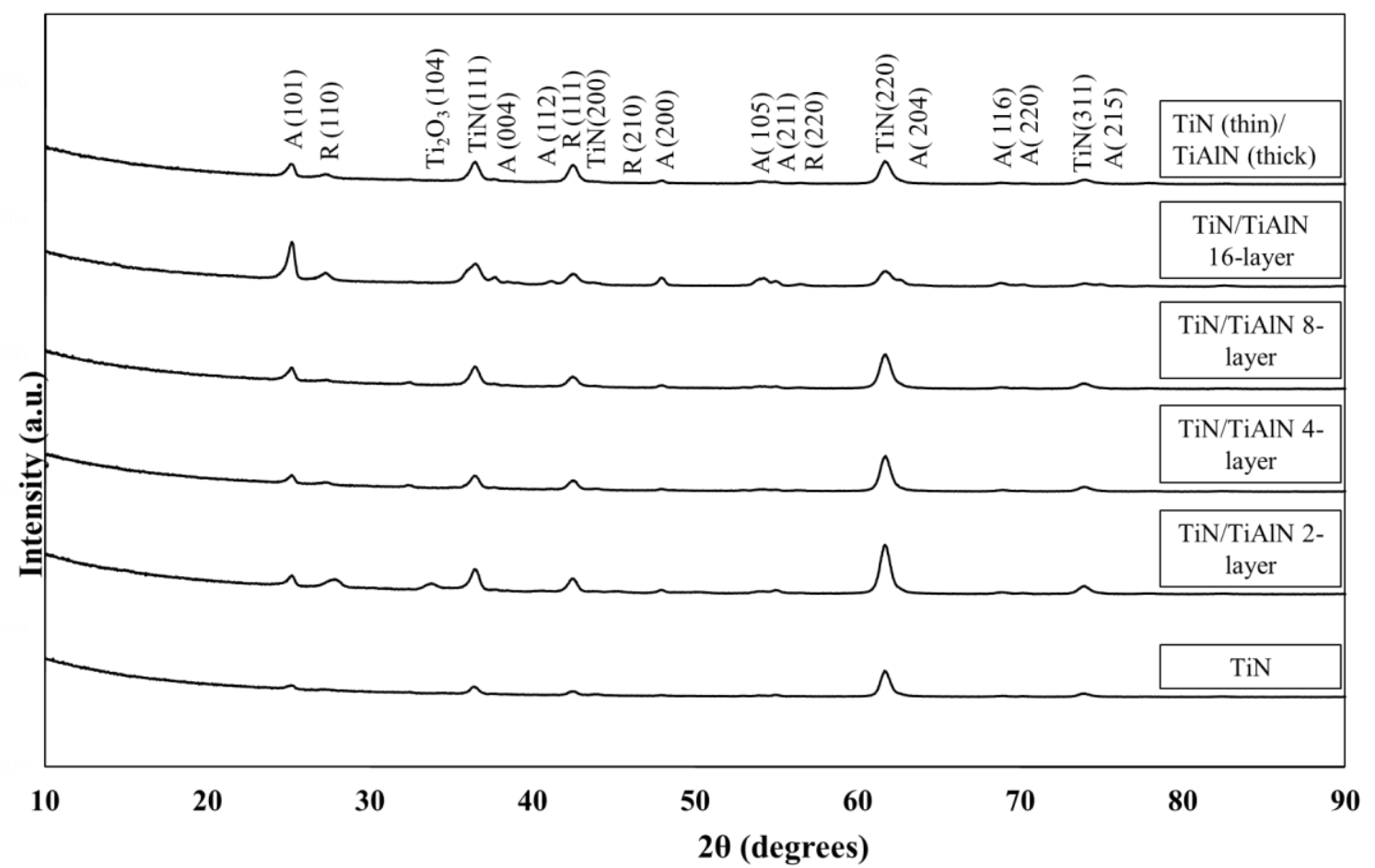

Figure 6. GI XRD patterns of samples that were exposed to the autoclave test at $360^{\circ} \mathrm{C}$ and saturation pressure of $18.7 \mathrm{MPa}$ for 33 days. GI XRD measurement was conducted with an incident angle of $1^{\circ}$. The penetration depth was calculated to be $\sim 1 \mu \mathrm{m}$, and assuming the density as $5.5 \mathrm{~g} / \mathrm{cm}^{3}$ for TiN.

Secondary Electron SEM images of the surface topography of the 33-day autoclave tested samples are presented in Figure 7. Although macro-particles were observed on the surface, no spallation, delamination or cracks were observed on the surface, indicating good adherence between coating and substrate and good coating durability in the corrosion environment for 33 days. The composition of these macro-particles were determined both from surface and cross section using EDS point analysis. Surface analysis showed that macro-particles were composed 
of $\sim 65$ at. $\%$ oxygen and $\sim 15$ at.\% titanium, the rest being mostly iron, carbon, chromium and nickel due to contamination from the autoclave. However, cross sectional analyses revealed that the macro-particles extended through the layers, exhibiting a composition proportional with the composition of the corresponding layer. Wave-like structures along the horizontal direction periodically occur in the vertical direction with an elevated region of width $\sim 1 \mu \mathrm{m}$ thick, which was attributed to the morphology of the as-polished substrate surface.

(a)

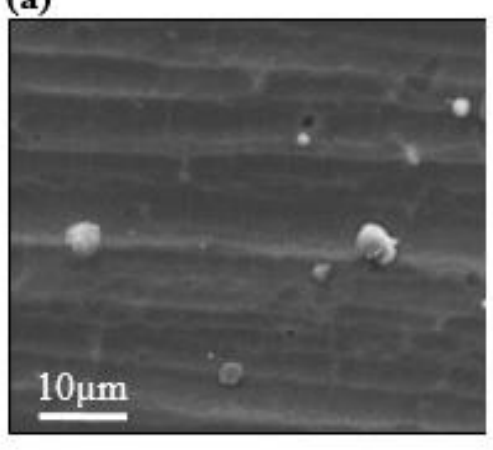

(d)

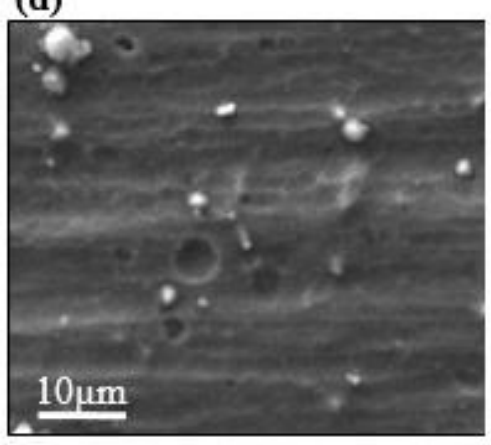

(b)

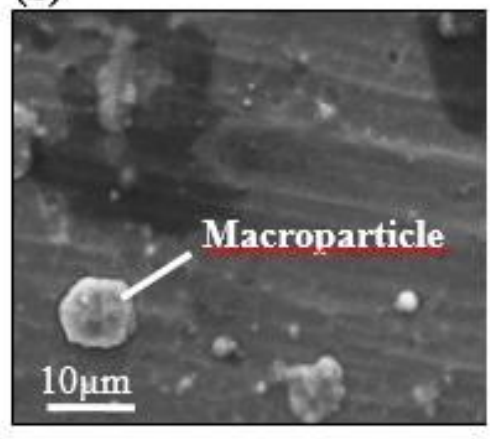

(e)

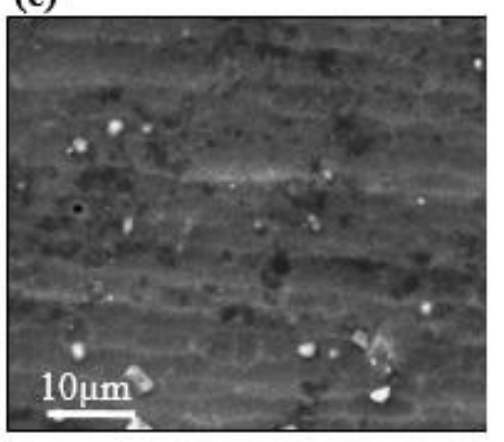

(c)

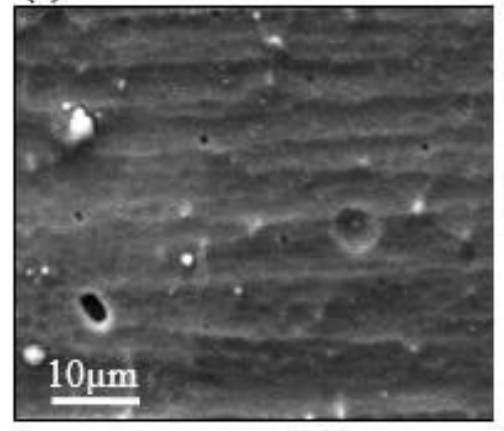

(f)

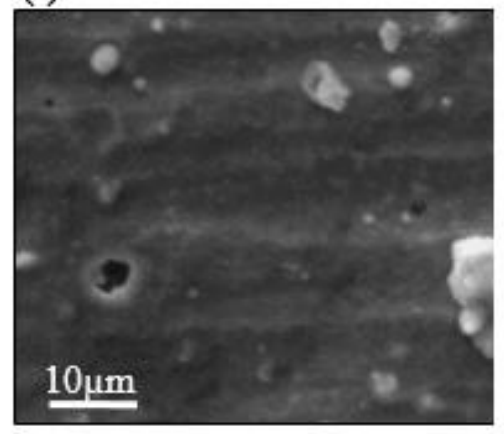

Figure 7. SEM-SE surface image of samples after the autoclave test at $360^{\circ} \mathrm{C}$ and saturation pressure of $18.7 \mathrm{MPa}$ for 33 days, which were coated with: (a) E21-TiN, (b) E22TiN(thin)/TiAlN(thick), (c) E23-TiN/TiAlN 2-layer, (d) E24-TiN/TiAlN 4-layer, (e) E25TiN/TiAlN 8-layer, and (f) E26-TiN/TiAlN 16-layer. No crack or delamination/spallation was observed. 
Cross section SEM micrographs of the layers are shown in Figure 8. The layer thicknesses are quite uniform from layer to layer. The coating layers are dense and well adherent to each other and to the ZIRLO ${ }^{\circledR}$ substrate, even after 33 days of autoclave test. Coating thicknesses were corresponded well to the target values shown in Table 1.

(a)

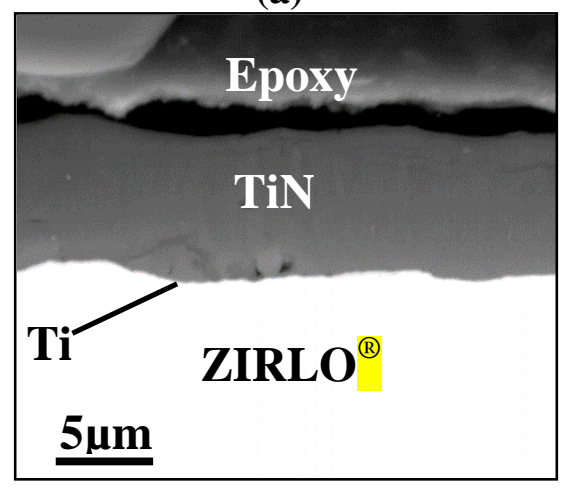

(c)

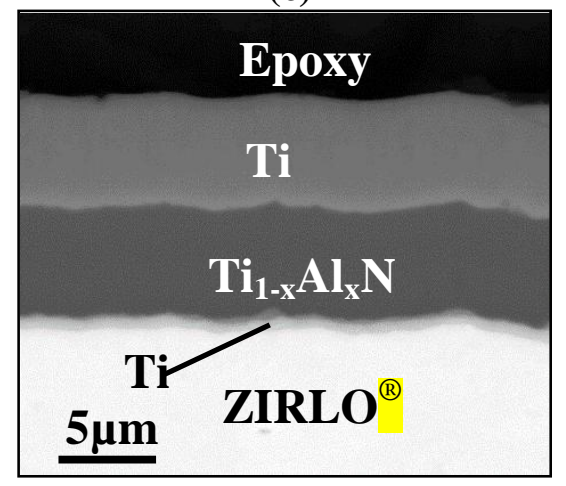

(e)

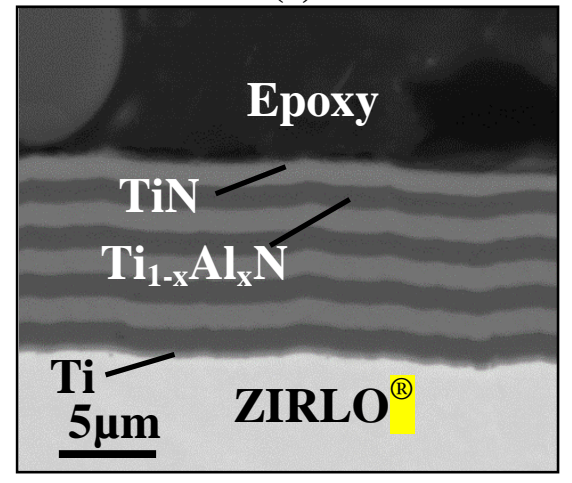

(b)

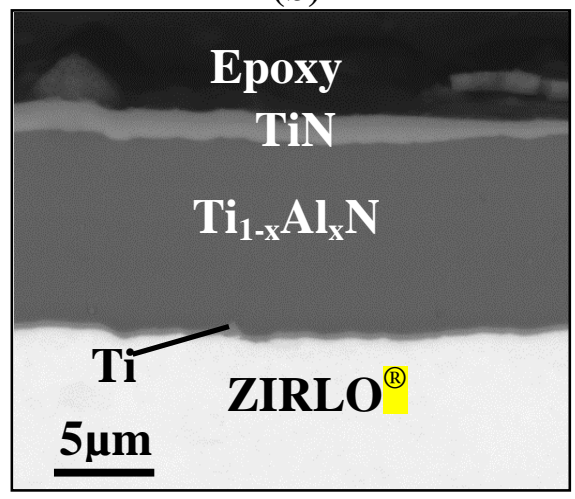

(d)

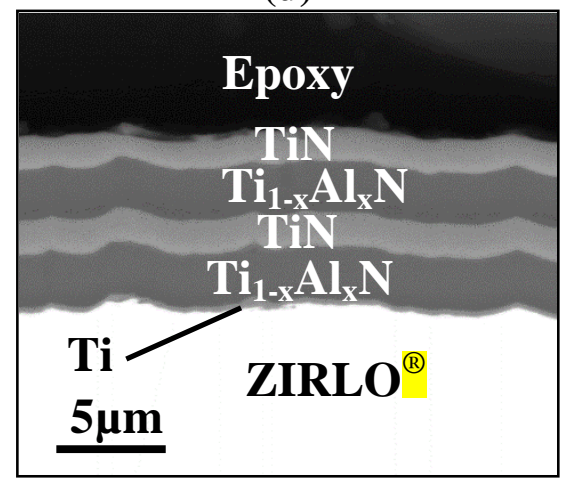

(f)

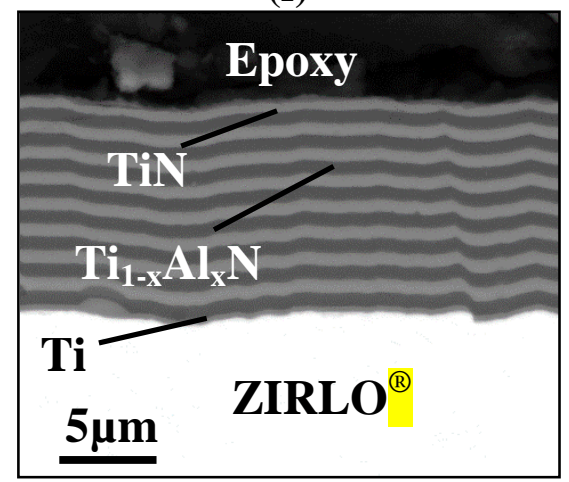

Figure 8. SEM-BSE cross section image after autoclave test at $360^{\circ} \mathrm{C}$ and saturation pressure of 18.7 MPa for 33 days: (a) E21-TiN, (b) E22-TiN(thin)/TiAlN(thick), (c) E23-TiN/TiAlN 2-layer, (d) E24-TiN/TiAlN 4-layer, (e) E25-TiN/TiAlN 8-layer, and (f) E26-TiN/TiAlN 16-layer. No 
crack or delamination/spallation was observed, indicating good corrosion resistance. These SEM images demonstrates that only a thin TiN layer is required as a barrier to minimize Al migration and prevent Boehmite formation.

The coating composition was evaluated using EDS to assess the coating effectiveness in preventing oxygen ingress. EDS spectra (taken from E22 and E23) revealed the composition of the TiAlN layers as 16 at.\% Ti, 32 at.\% $\mathrm{Al}$ and 52 at.\% N, in good agreement with the cathode composition of 33 at.\% $\mathrm{Ti}$ and 67 at.\% $\mathrm{Al}$ and it is expected that cathode composition dictates the coating composition in PVD processes [19].

Figure 9a shows the oxygen profile and Figure 9b shows a line scan of the multilayer coating for TiN/TiAlN 8-layer coated sample. Figure 9a shows that oxygen penetrated only to a distance of $\sim 1.5 \mu \mathrm{m}$, corresponding only to the outermost TiN layer. This means that little or no no oxide forms on the subsequent layers of the coating or at the substrate and coating interface. As we reach to the substrate interface, an increase in the oxygen was observed which was the oxygen that was already present when the alloy was produced, which is acceptable up in the range of 0.09-0.16 wt.\% [41]. Very little oxygen was seen within the multilayers as shown in the line scan in $9 \mathrm{~b}$.

(a)

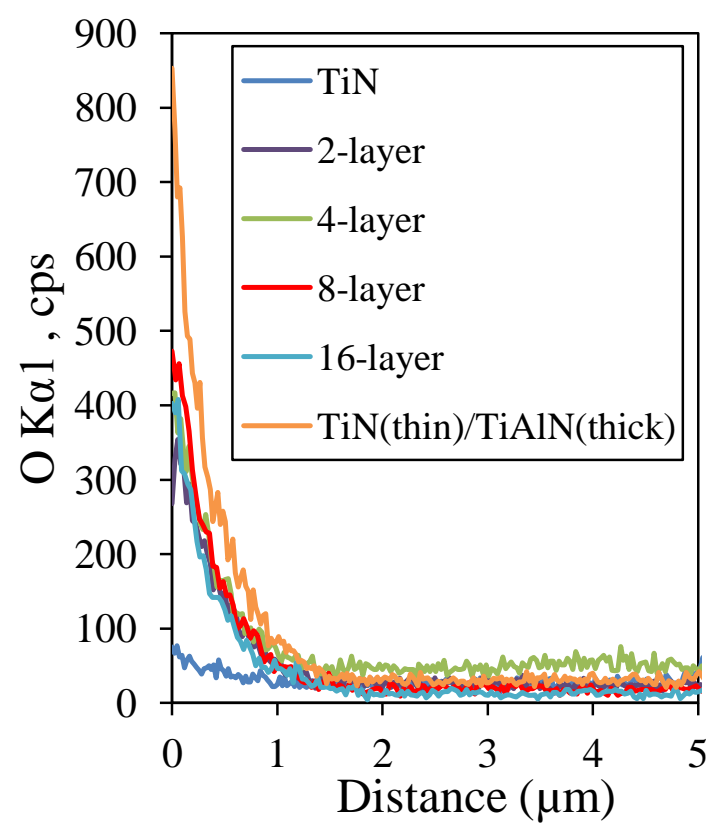

(b)
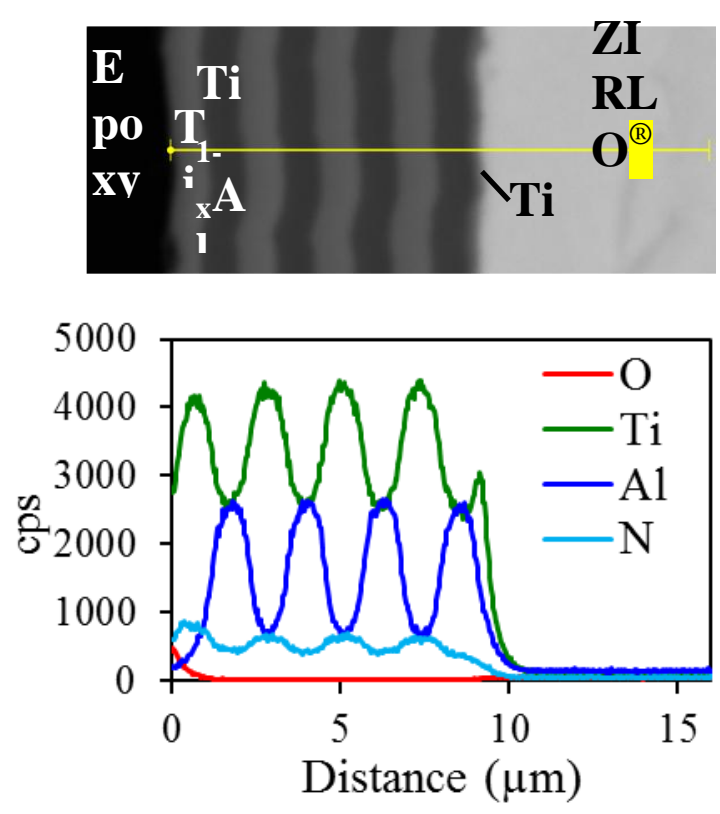

Figure 9. EDS cross section line spectrum after autoclave test at $360^{\circ} \mathrm{C}$ and saturation pressure of 18.7 MPa for 33 days, (a) oxygen profile through TiN, 2-layer, 4-layer, 8-layer, 16-layer and TiN 
(thin)/TiAlN(thick) coating starting from the outer layer towards the substrate and (b) oxygen, titalnium, aluminum and nitrogen profile through cross section of E25-(TiN/TiAlN 8layer)/Ti/ZIRLO ${ }^{\circledR}$ sample.

\subsection{Autoclave tested samples for 90 days}

The samples that were autoclave tested for 90 days demonstrated a weight gain in the range of 1.6-6.0 mg/dm², again much lower values than those of uncoated ZIRLO ${ }^{\circledR}\left(40 \mathrm{mg} / \mathrm{dm}^{2}\right.$ after 90 days autoclave test). Some samples did show weight loss (in addition to TiN(thin)/TiAlN(thick) 2-layered and 4-layered coating), indicating spallation/delamination of the coating. Samples coated with TiN, TiN/TiAlN 8-layer and 16-layer showed no decrease in the weight gain data during 90 days, no spallation/delamination determined by visual examination. Thus, these optimized coatings were able to withstand $360^{\circ} \mathrm{C}$ water corrosion environment without spallation/delamination for 90 days. Among these, two multilayered coating designs (8- and 16-layered), 8-layered samples showed the minimum positive weight gain. Considering the ease of manufacturability while comparing 8-and 16- layered coatings, the 8-layer design architecture would be the most desirable. Thus, the TiN/TiAlN 8-layer coating was determined to be the optimum architecture that makes it possible to both stop boehmite phase formation, show good adhesion, and to have the lowest weight gain without spallation or delamination.

\section{Conclusion}

In this study, TiN and TiAlN multilayer coatings with various architectures were deposited on ZIRLO ${ }^{\circledR}$ coupons according to the previously determined deposition parameters, Ti bond coating with thickness of $0.6 \mu \mathrm{m}$ and a substrate surface with $0.25 \mu \mathrm{m} \mathrm{R}_{\mathrm{a}}$ roughness. The main aim was to determine the optimum multilayer architecture and determine minimum TiN top layer thickness to achieve a coating that would withstand $360^{\circ} \mathrm{C}$ water exposure for 90 days with minimal weight gain, no boehmite phase formation, no penetration of oxygen, no cracking and no debonding. 
A thin layer of $(\sim 1 \mu \mathrm{m})$ TiN as a barrier is sufficient to stop $\mathrm{Al}$ migration and prevent boehmite phase formation. All coatings were able to withstand the autoclave test without any spallation/delamination up to 7 days and most coatings were adherent to the surface for up to 33 days. At the end of 90 days, TiN/TiAlN 8-layer architecture coatings showed the best corrosion performance at $360^{\circ} \mathrm{C}$ and $18.7 \mathrm{MPa}$ (saturation pressure) compared to other tested multilayer architectures due to no boehmite phase formation, positive weight gain data without any delamination/spallation and prevention of oxygen ingress prevention.

We conclude that the best architecture developed ( 8 and 16-layer TiN/TiAlN multilayer coatings) showed approximately an order of magnitude lower weight gain compared to uncoated ZIRLO $^{\circledR}$ substrate and no delamination or spallation.

We continue to perform research in this area to develop coatings that can withstand higher temperatures to create an accident tolerant fuel, as will be discussed in upcoming publications.

\section{Acknowledgements}

This research was sponsored by the U.S. Department of Energy, Office of Nuclear Energy, Nuclear Engineering University Programs (NEUP), under grant number DE-AC07$05 \mathrm{ID} 14517$. 


\section{References}

[1] D.Q. Peng, X.D. Bai, F. Pan, H. Sun, B.S. Chen, Influence of aluminum ions implanted on oxidation behavior of ZIRLO alloy at $500^{\circ} \mathrm{C}$, Vacuum. 80 (2006) 530-536. doi:10.1016/j.vacuum.2005.08.026.

[2] C. Lemaignan, A.T. Motta, Zirconium Alloys in Nuclear Applications, in: B.R.T. FrostB (Ed.), Mater. Sci. Technol. A Compr. Treat., New York: VCH, 1994: pp. 1-51. doi:10.1016/0149-1970(96)00005-4.

[3] R.S. Daum, Y.S. Chu, A.T. Motta, Identification and quantification of hydride phases in Zircaloy-4 cladding using synchrotron X-ray diffraction, J. Nucl. Mater. 392 (2009) 453463. doi:10.1016/j.jnucmat.2009.04.004.

[4] N.P. Neureiter, B.J. Garrick, R.A. Bari, J. Beard, Percy M., M.Q. Brewster, M.L. Corradini, et al., Lessons learned from the Fukushima nuclear accident for improving safety of U.S. Nuclear Plants, 2014.

[5] K.A. Terrani, S.J. Zinkle, L.L. Snead, Advanced oxidation-resistant iron-based alloys for LWR fuel cladding, J. Nucl. Mater. 448 (2014) 420-435. doi:10.1016/j.jnucmat.2013.06.041.

[6] L. Hallstadius, S. Johnson, E. Lahoda, Cladding for high performance fuel, Prog. Nucl. Energy. 57 (2012) 71-76. doi:10.1016/j.pnucene.2011.10.008.

[7] Shannon M. Bragg-Sitton, Advanced LWR Nuclear Fuel Cladding System Development: Technical Program Plan, 2012.

[8] K. Barrett, S. Bragg-Sitton, D. Galicki, Advanced LWR Nuclear Fuel Cladding System Development Trade-off Study, Idaho Falls, IDaho, 2012.

[9] F. Khatkhatay, L. Jiao, J. Jian, W. Zhang, Z. Jiao, J. Gan, et al., Superior corrosion resistance properties of TiN-based coatings on Zircaloy tubes in supercritical water, J. Nucl. Mater. 451 (2014) 346-351. doi:10.1016/j.jnucmat.2014.04.010.

[10] I. Kim, F. Khatkhatay, L. Jiao, G. Swadener, J.I. Cole, J. Gan, et al., TiN-based coatings on fuel cladding tubes for advanced nuclear reactors, J. Nucl. Mater. 429 (2012) 143-148. doi:10.1016/j.jnucmat.2012.05.001.

[11] E. Alat, A.T. Motta, R.J. Comstock, J.M. Partezana, D.E. Wolfe, Ceramic coating for corrosion (c3) resistance of nuclear fuel cladding, Surf. Coatings Technol. in Press, (2015). doi:10.1016/j.surfcoat.2015.08.062.

[12] S.K. Han, Jeon G., Yoon, Joo S., Kim, Hyung J., High temperature wear resistance of (TiAl)N films synthesized by cathodic arc plasma deposition, Surf. Coatings Technol. 8687 (1996) 82-87.

[13] K.L. Lin, M.Y. Hwang, C.D. Wu, The deposition and wear properties of cathodic arc plasma deposition TiAlN deposits, Mater. Chem. Phys. 46 (1996) 77-83. doi:10.1016/0254-0584(96)80134-9.

[14] J.G. Han, K.H. Nam, I.S. Choi, The shear impact wear behavior of Ti compound coatings, Wear. 214 (1998) 91-97. doi:10.1016/S0043-1648(97)00205-6. 
[15] Y. Wang, A study of PVD coatings and die materials for extended die-casting die life, Surf. Coatings Technol. 94-95 (1997) 60-63. doi:10.1016/S0257-8972(97)00476-3.

[16] T. Suzuki, D. Huang, Y. Ikuhara, Microstructures and grain boundaries of (Ti,Al)N films, Surf. Coatings Technol. 107 (1998) 41-47. doi:10.1016/S0257-8972(98)00550-7.

[17] R.D. James, D.L. Paisley, K.A. Gruss, S. Parthasarthi, B.R. Tittmann, Y. Horie, et al., Adhesion evaluation of TiN and (Ti, Al)N coatings on titanium 6Al-4V, Mater. Res. Soc. Symp. Proc. 410 (1996) 377-382.

[18] A. Anders, Surface \& Coatings Technology A review comparing cathodic arcs and high power impulse magnetron sputtering ( HiPIMS ), Surf. Coat. Technol. 257 (2014) 308325. doi:10.1016/j.surfcoat.2014.08.043.

[19] S. PalDey, S. Deevi, Single layer and multilayer wear resistant coatings of (Ti, Al) N: a review, Mater. Sci. Eng. A. 342 (2003) 58-79. doi:10.1016/S0921-5093(03)00473-8.

[20] K. Tönshoff, a. Mohlfeld, T. Leyendecker, H.G. Fuß, G. Erkens, R. Wenke, et al., Wear mechanisms of (Til - x,Alx)N coatings in dry drilling, Surf. Coatings Technol. 94-95 (1997) 603-609. doi:10.1016/S0257-8972(97)00504-5.

[21] W.-D. Münz, Titanium aluminum nitride films: A new alternative to TiN coatings, J. Vac. Sci. Technol. A. 4 (1986) 2717. doi:10.1116/1.573713.

[22] T. Ikeda, S. Satoh, Phase formation and characterization of hard coatings in the Ti-Al-N system prepared by the cathodic arc ion plating method, Thin Solid Films. 195 (1991) 99110. doi:10.1016/0040-6090(91)90262-V.

[23] A. Anders, Some Applications of Cathodic Arc Coatings, in: Cathodic Arcs From Fractal Spots to Energ. Condens., Springer Science \& Business Media, 2008: pp. 429-490. doi:10.1007/978-0-387-79108-1.

[24] B.F. Coll, R. Fontana, A. Gates, P. Sathrum, (Ti-Al)N advanced films prepared by arc process, Mater. Sci. Eng. A. 140 (1991) 816-824. doi:10.1016/0921-5093(91)90519-S.

[25] J.T.M. De Hosson, N.J.M. Carvalho, Y. Pei, D. Galvan, Electron Microscopy Characterization of Nanostructured Coatings, in: A. Cavaleiro, J.T.M. De Hosson (Eds.), Nanostructured Coatings, Springer Science \& Business Media, 2006: pp. 143-215.

[26] M. Zhou, Y. Makino, M. Nose, K. Nogi, Phase transition and properties of Ti-Al-N thin films prepared by r.f.-plasma assisted magnetron sputtering, Thin Solid Films. 339 (1999) 203-208. doi:10.1016/S0040-6090(98)01364-9.

[27] K. Daub, R. Van Nieuwenhove, H. Nordin, Investigation of the impact of coatings on corrosion and hydrogen uptake of Zircaloy-4, J. Nucl. Mater. 467 (2015) 260-270. doi:10.1016/j.jnucmat.2015.09.041.

[28] O. Durand-Drouhin, A.E. Santana, A. Karimi, V.H. Derflinger, A. Schütze, Mechanical properties and failure modes of $\mathrm{TiAl}(\mathrm{Si}) \mathrm{N}$ single and multilayer thin films, Surf. Coatings Technol. 163-164 (2003) 260-266. doi:10.1016/S0257-8972(02)00609-6.

[29] T. Björk, R. Westergård, S. Hogmark, J. Bergström, P. Hedenqvist, Physical vapour deposition duplex coatings for aluminium extrusion dies, Wear. 225-229 (1999) 11231130. doi:10.1016/S0043-1648(99)00089-7.

[30] H.C. Barshilia, M.S. Prakash, A. Jain, K.S. Rajam, Structure, hardness and thermal 
stability of TiAlN and nanolayered TiAlN/CrN multilayer films, Vacuum. 77 (2005) 169179. doi:10.1016/j.vacuum.2004.08.020.

[31] L.A. Dobrzański, K. Lukaszkowicz, A. Zarychta, L. Cunha, Corrosion resistance of multilayer coatings deposited by PVD techniques onto the brass substrate, J. Mater. Process. Technol. 164-165 (2005) 816-821. doi:10.1016/j.jmatprotec.2005.02.081.

[32] A. Rizzo, L. Mirenghi, M. Massaro, U. Galietti, L. Capodieci, R. Terzi, et al., Improved properties of TiAlN coatings through the multilayer structure, Surf. Coatings Technol. 235 (2013) 475-483. doi:10.1016/j.surfcoat.2013.08.006.

[33] T. Weirather, K. Chladil, B. Sartory, D. Caliskanoglu, R. Cremer, W. Kölker, et al., Increased thermal stability of Til-xAlxN/TiN multilayer coatings through high temperature sputter deposition on powder-metallurgical high-speed steels, Surf. Coatings Technol. 257 (2014) 48-57. doi:10.1016/j.surfcoat.2014.06.018.

[34] L.A. Dobrzañski, K. Lukaszkowicz, Corrosion resistance of multilayer and gradient coatings deposited by PVD and CVD techniques, Arch. Mater. Sci. Eng. 28 (2007) 12-18.

[35] D. Mattox, Handbook of Physical Vapour Deposition (PVD) Processing: Film Formation, Adhesion, Surface Preparation and Contamination Control, Noyes Publications, 1998. doi:10.1080/10426919908907566.

[36] J.E. Daalder, Cathode spots and vacuum arcs, Phys. B+C. 104 (1981) 91-106. doi:10.1016/0378-4363(81)90040-1.

[37] W.D. Sproul, Physical vapor deposition tool coatings, Surf. Coatings Technol. 81 (1996) 1-7. doi:10.1016/0257-8972(95)02616-9.

[38] M. Ahlgren, H. Blomqvist, Influence of bias variation on residual stress and texture in TiAlN PVD coatings, Surf. Coatings Technol. 200 (2005) 157-160. doi:10.1016/j.surfcoat.2005.02.078.

[39] Y. Liu, I. Bhamji, P.J. Withers, D.E. Wolfe, A.T. Motta, M. Preuss, Evaluation of the interfacial shear strength and residual stress of TiAlN coating on ZIRLO ${ }^{\mathrm{TM}}$ fuel cladding using a modified shear-lag model approach, J. Nucl. Mater. (2015). doi:10.1016/j.jnucmat.2015.06.003.

[40] I. Younker, M. Fratoni, Neutronic evaluation of coating and cladding materials for accident tolerant fuels, Prog. Nucl. Energy. 88 (2016) 10-18. doi:10.1016/j.pnucene.2015.11.006.

[41] H.H. Shah, Optimized ZIRLO ${ }^{\mathrm{TM}} *$ Westinghouse, 2006. 